ISSN 1518-3483

Licenciado sob uma Licença Creative Commons

\title{
História da Matemática: história de uma disciplina
}

\author{
History of Mathematics: history of a discipline
}

\section{Maria Cristina Araújo de Oliveira ${ }^{[a]}$, Wagner da Cunha Fragoso ${ }^{[b]}$}

[a] Doutora em Educação Matemática, professora adjunta do Mestrado Profissional em Educação Matemática da Universidade Federal de Juiz de Fora, Juiz de Fora, MG - Brasil, e-mail: mcrisoliveira6@gmail.com

[b] Mestre Profissional em Educação Matemática, professor do Colégio Militar de Juiz de Fora, Juiz de Fora, MG - Brasil, e-mail: wfragoso2001@yahoo.com.br

\section{Resumo}

Este artigo apresenta a trajetória histórica da disciplina História da Matemática no curso de formação de professores de Matemática da Universidade Federal de Juiz de Fora, situando-a no contexto de sua institucionalização nos currículos. Trata-se de um estudo local, cujos resultados evidenciam conclusões "glocais". O estudo revela três momentos de mudanças na condução da disciplina: inicialmente é tratada como uma disciplina de Matemática; num segundo momento, há uma ruptura nessa abordagem e a Matemática passa a ser estudada historicamente; o terceiro momento não caracteriza propriamente uma ruptura, mas a inclusão de novos conteúdos, relativos à história da educação matemática, particularmente à história da Matemática escolar. Tais mudanças são explicadas a partir da renovação do corpo docente, da formação e da atuação em pesquisa dos 
professores responsáveis pela disciplina, e das possibilidades criadas pela própria natureza da História da Matemática.

Palavras-chave: História da educação matemática. História das disciplinas. História da Matemática. Formação de professores de matemática.

\section{Abstract}

This article discusses the historical path of the discipline of History of Mathematics in the Mathematics' teachers education of Universidade Federal de Juiz de Fora, in the context of the curriculum consolidation. It's a local study with "glocal" conclusions. The article shows three moments of change in the discipline's teaching: at first, it's seem as Math's discipline; then it has worked to teach the math's history; and finally it adds news contents, concerning the history of math's education, especially the history of the Mathematics in schools. These changes happened with the renovation of the teachers, the formation and the research work of teachers and the possibilities emerging from the nature of the History of Mathematics.

Keywords: History of mathematics education. History of school subjects. History of Mathematics. Mathematics teacher education.

\section{Introdução}

A História da Matemática há muito é vista como um conteúdo potencialmente rico para os processos de ensino e de aprendizagem de Matemática bem como para a formação dos professores dessa disciplina. $\mathrm{Na}$ atualidade, parece haver consenso de sua importância na formação de professores que ensinam Matemática. Contudo, isso não acontece quanto às abordagens a serem dadas à História da Matemática como disciplina em curso de formação de professores. Pela própria natureza híbrida, transitando entre duas grandes áreas do conhecimento - a História e a Matemática -, ela permite variados enfoques e abordagens 
metodológicas, o que leva às configurações bastante diversas para uma mesma disciplina.

Este artigo apresenta a história da disciplina História da Matemática no curso de formação de professores de Matemática da Universidade Federal de Juiz de Fora (UFJF). O recorte temporal compreende a criação da disciplina e sua inserção no currículo, em 1981, até os dias atuais. As questões que nortearam o estudo que deu origem ao presente artigo referem-se às condições de criação e inserção da disciplina no referido curso e às transformações dela ao longo do tempo.

Trata-se de um estudo local que permite caracterizar diferentes modos de conduzir a disciplina de História da Matemática, porém cujos resultados permitem formular considerações que, no diálogo com outros estudos, possibilitam uma análise "glocal", segundo Chartier (2007). Essa investigação revela uma tendência na condução dessa disciplina que se constitui a partir da participação de educadores matemáticos no grupo de professores responsáveis pela História da Matemática.

\section{História da Matemática como disciplina}

A História da Matemática é vista já há algum tempo como uma possibilidade de despertar o interesse de alunos que estudam Matemática e de contribuir para suas aprendizagens. No Brasil, por exemplo, os livros de Euclides Roxo a partir do final da década de 1920 apresentam diversas notas históricas ${ }^{1}$.

Assim, as possibilidades criadas pela História da Matemática a tornam objeto de discussão particularmente no que diz respeito à formação de professores de Matemática. Jones (1976, p. 5), em um texto intitulado Mathematics as a teaching tool, registrou que "recomendações para a inclusão de algum estudo de história em programas de treinamento de professores podem ser encontradas em estudos e relatórios de

\footnotetext{
1 Por exemplo, Curso de Matemática Elementar. Rio de Janeiro: Francisco Alves, 1929.
} 
comitês de muitos países" (apud MIGUEL; BRITO, 1996, p. 47). Souto (2003) afirma que o texto elaborado por J. Fauvel e J. Maanen sob o título de History in Mathematics Education, publicado em 2000 no International Commission on Mathematical Instruction (ICMI) Study², evidencia que historiadores da Matemática e educadores matemáticos, há algum tempo, reconhecem a importância da História da Matemática na formação do professor e preocupam-se com a inserção desse tema nessa formação. Em 1904, no III Congresso Internacional de Matemática, em Heidelberg, na Alemanha, aprovou-se uma moção proposta por matemáticos, historiadores da Matemática e educadores matemáticos, recomendando a introdução de componentes históricos na formação de professores. O efeito dessa moção se fez sentir, nos anos seguintes, pela tendência de introduzir a História da Matemática nessa formação (SOUTO, 2003).

Um levantamento de Phillip S. Jones ${ }^{3}$, em 1969 (apud MIGUEL; BRITO, 1996), registrou que John A. Schumaker (1961) mostrou que, no período compreendido entre 1920 e 1958, a porcentagem de instituições de formação de professores para a escola secundária nos Estados Unidos que ofereciam o curso de História da Matemática passou de 44 para 52. Tal curso era exigido de todos os professores de Matemática na então União Soviética.

No Brasil, a preocupação com a função da disciplina História da Matemática na formação do professor de Matemática aparece no I Encontro Paulista de Educação Matemática (I Epem), realizado na cidade de Campinas, em outubro de 1989. Nessa ocasião, ficou constatada a pouca oferta da disciplina História da Matemática nos currículos brasileiros de Licenciatura em Matemática. Com referência a esse encontro, Miguel e Brito (1996) argumentam que:

2 Trabalho realizado por educadores matemáticos de vários países que organizou as diversas contribuições da História da Matemática para o ensino, sob pontos de vista de caráter filosófico, interdisciplinar e cultural.

3 Presidente da Associação Matemática da América Comissão de Filmes de Instrução da sala de aula (1955-1959) e Presidente do Conselho Nacional de Professores de Matemática (NCTM) (1960-1962). 
Ocorreu uma atividade coordenada denominada "Aspectos Históricos no Processo de Ensino-aprendizagem da Matemática", na qual foi levantado o problema referente à função do estudo da História da Matemática na formação do professor de matemática. Nessa ocasião, os participantes dessa atividade destacaram a "lamentável ausência da disciplina História da Matemática, quer na quase totalidade dos currículos de licenciatura, quer na quase totalidade dos cursos de magistério" e que há pequena oferta de cursos de História da Matemática para professores em exercício (MIGUEL; BRITO, 1996, p. 48).

Essa mesma problemática foi discutida no IV Encontro Nacional de Educação Matemática (IV Enem), em Blumenau, SC, em janeiro de 1992, no I Seminário Nacional de História da Matemática (I SNHM), realizado em Recife, PE, em abril de 1995, e no V Encontro Nacional de Educação Matemática (V Enem), realizado em Aracaju, SE, em julho de 1995. Esses foram os primeiros passos que iriam convergir para que a disciplina História da Matemática viesse, anos mais tarde, a vigorar, quase que na totalidade, das grades curriculares dos cursos de licenciatura em Matemática, em âmbito nacional.

No decorrer do tempo, a legislação incorpora, em alguma medida, as propostas de inclusão da História da Matemática no currículo dos cursos de formação de professores de Matemática. Mais precisamente em 5 de fevereiro de 1998, está registrado na Portaria n. 57, publicado no Diário Oficial da União em 6 de fevereiro de 1998 para o Exame Nacional do Curso de Matemática de 1998, o perfil dos graduandos, no qual se destaca que esses profissionais deveriam ter uma visão histórica e crítica da Matemática, tanto no seu estado atual como nas várias fases de sua evolução. Para os licenciandos, especificamente, a História da Matemática aparece como um conteúdo a ser avaliado.

Nos últimos tempos, os currículos dos cursos de formação de professores vêm se moldando à Lei de Diretrizes e Bases da Educação Nacional Lei n. 9.394, de 20 de dezembro de 1996 - e às Diretrizes Curriculares para Cursos de Matemática de 2001. Tais documentos conduzem à inserção da disciplina História da Matemática nos cursos de formação de professores. 
Em 5 de dezembro de 2001, publicou-se o Parecer CNE/ CES 1.302/2001, Diretrizes Curriculares Nacionais para os Cursos de Matemática, Bacharelado e Licenciatura. Nesse documento, verifica-se a inclusão da História da Matemática nos cursos de formação de professores de Matemática, em nível superior, integrando a chamada "parte comum". Nele, registra-se o parecer do relator, o qual indica que tal documento é a sistematização das discussões apresentadas pelos diversos órgãos, entidades e instituições à Secretaria da Educação Superior do Ministério da Educação (SESu/MEC) sobre a organização curricular do curso de Matemática, em termos do bacharelado e da licenciatura. Com a determinação estabelecida nas Diretrizes Curriculares Nacionais para os cursos de Matemática - bacharelado e licenciatura, a disciplina História da Matemática, atualmente, se faz presente na grade curricular da maioria das instituições de ensino superior que oferecem o curso de licenciatura em Matemática.

No Estado de Minas Gerais, no curso de licenciatura em Matemática da UFJF, a disciplina História da Matemática foi formalmente incluída no currículo, em 1981, mas ministrada pela primeira vez em 1987. Mais duas universidades federais mineiras a incluíram em seus currículos na década de 1980: a Universidade Federal de Uberlândia (UFU), em 1982; e a Universidade Federal de Minas Gerais (UFMG), em 1989. Minas Gerais conta atualmente com 11 universidades federais e em todas elas a História da Matemática é uma disciplina obrigatória do curso de licenciatura em Matemática.

Observa-se que dentre as universidades federais de Minas Gerais examinadas, a Universidade Federal de Minas Gerais (UFMG), a Universidade Federal de Juiz de Fora (UFJF), a Universidade Federal de Lavras (UFLA), a Universidade Federal de Uberlândia (UFU) e a Universidade Federal de São João Del Rei (UFSJ) são as únicas cujo acesso a ementa da disciplina História da Matemática é possível via internet. Para as demais universidades, Universidade de Alfenas (Unifal), Universidade Federal de Itajubá (Unifei), Universidade Federal dos Vales do Jequitinhonha e Mucuri (UFVJM), Universidade Federal do Triângulo Mineiro (UFTM), 
Universidade Federal de Viçosa (UFV) e Universidade Federal de Ouro Preto (Ufop), só há possibilidade de se consultar a grade curricular.

No exame das ementas e das grades curriculares disponibilizadas, observa-se que a disciplina História da Matemática é oferecida nos períodos finais, a partir do quinto. Ainda que não haja pré-requisito oficialmente registrado, o fato de compor os períodos finais pode sinalizar que os conhecimentos matemáticos adquiridos durante os períodos iniciais representam os necessários conteúdos para a realização dessa disciplina. A carga horária perfaz um mínimo de 60 horas em todos os cursos pesquisados, com exceção de Viçosa, onde são destinadas apenas 30 horas.

Também se pode concluir, a partir desse exame, que todas as universidades federais mineiras descrevem o início da disciplina pelo estudo da Matemática dos povos antigos (egípcios, mesopotâmios, gregos, árabes e chineses). Em seguida, estuda-se a Matemática na Europa Medieval até o século XIX. Somente a Unifal e a UFLA explicitam na ementa a intenção de propor o estudo do desenvolvimento da História da Matemática como um recurso didático para as aulas de Matemática no ensino fundamental e médio. A UFU propõe estudar o século XX, abordando a revisão crítica dos fundamentos da Matemática. Entre as ementas consultadas, observa-se que os objetivos visam a proporcionar uma visão histórica do desenvolvimento do conhecimento matemático inserido no contexto sociocultural, desde os antigos gregos até o desdobramento do mundo contemporâneo.

Na UFJF, onde foi possível, pela pesquisa, acompanhar as transformações da disciplina, a partir de 2009, acrescentam-se assuntos que intencionam discutir questões relativas à prática do professor de Matemática. Nessa perspectiva, desenvolve-se um estudo histórico sobre a Matemática escolar a partir da leitura e da discussão de literatura de história da educação matemática e da análise de livros didáticos de diferentes momentos dessa história.

Duas universidades diferem ao colocar explicitamente, nos documentos disponíveis, a ligação da História da Matemática com a formação do professor: a Ufla, que pretende desenvolver análise crítica do uso 
da história no ensino com vistas ao planejamento de unidades didáticas, e a UFU, que propõe, a partir da análise crítica da evolução do método axiomático, conduzir a uma ação transformadora na prática profissional ${ }^{4}$. Certamente, a manifestação desse tipo de ação dependerá muito da metodologia de ensino estabelecida pelo docente responsável em ministrar as aulas de História da Matemática, bem como do respectivo corpo discente.

Em termos da bibliografia básica para a disciplina História da Matemática, somente foi possível a identificação em cinco universidades mineiras: UFMG, UFJF, Ufla, UFU e UFSJ. Nessas, é unânime a escolha da obra de Carl Benjamin Boyer, História da Matemática. Há outras indicações, como Introdução à História da Matemática, de Howard Eves; História Concisa das Matemáticas, de D. J. Struik; e História Ilustrada da Ciência, de C. A. Ronan, obras traduzidas para a língua portuguesa. O livro de Carl Benjamin Boyer se constitui em parâmetro básico quando se trata do estudo e/ou ensino da História da Matemática em muitas instituições ensino superior. Acredita-se que essa escolha possa estar relacionada ao fato de que este é o primeiro texto de História da Matemática traduzido para a língua portuguesa, o que tornou mais fácil o acesso aos estudantes de graduação, além da seriedade e da respeitabilidade acadêmica de seu autor, entre outros fatores.

Do exposto, pode-se verificar que as ementas possuem trajetórias bastante similares e mesmo em relação à bibliografia há muitas interseções. Entretanto, a análise das práticas provavelmente revelará diferenças substanciais dadas as especificidades culturais das instituições, do corpo docente responsável pela História da Matemática e do corpo discente, entre outros fatores.

\section{A disciplina História da Matemática no curso de licenciatura da UFJF}

Tomando por base Chervel (1990) e Julia (2001), que definem uma disciplina escolar como combinação de inúmeros constituintes de

4 A análise mais detalhada desses documentos pode ser encontrada em Fragoso (2011). 
dimensões variáveis, tais como "os conteúdos ensinados, os exercícios, as práticas de motivação e de estimulação dos alunos, o corpo docente, o corpo discente, o aparelho docimológico [...]" (CHERVEL, 1990, p. 207; JULIA, 2001, p. 34), procurou-se investigar esses mesmos constituintes com relação à disciplina História da Matemática no curso de formação de professores de Matemática da UFJF.

Uma disciplina se configura a partir de um conjunto de conhecimentos, que podem ser estratificados e hierarquizados em diversos conteúdos. Dessa forma, ao longo de sua existência curricular, sofre transformações. Baseado no recente fenômeno de secundarização do ensino superior, Chervel (1990) afirma que a História da Matemática pode ser classificada como uma disciplina acadêmica e não como conteúdo.

Segundo Julia (2001), as práticas escolares são modificadas e inovadas conforme a mudança do público, que impõe a mudança dos conteúdos a serem ensinados. Cada novo público advindo de culturas diversas influencia os contextos escolares e, simetricamente, é influenciado por eles. Tal fenômeno pode ser visto também no ensino superior; por exemplo, é possível já identificar as necessárias transformações a partir da implementação recente do Programa de Apoio aos Planos de Reestruturação e Expansão das Universidades Federais (Reuni), que expandiu consideravelmente o número de matrículas nas instituições de ensino superior federais.

Julia (2001) ressalta, com relação à história das disciplinas escolares, que "Ela tenta identificar, tanto por meio das práticas de ensino utilizadas na sala de aula como, dos grandes objetivos que presidiram a constituição das disciplinas, o núcleo duro que pode constituir uma história renovada da educação" (JULIA, 2001, p. 13).

No olhar desse autor, um estudo na perspectiva da história cultural deve considerar como aspecto principal a identificação das fontes, sobre as quais sugere também o questionamento de seu rigor. Assim, no que se refere às fontes e à sua importância para a história das práticas culturais, Julia (2001) registra que há dificuldade de obtenção delas para a escrita da história que se passa dentro da escola e questiona: "A história 
das práticas culturais é, com efeito, a mais difícil de reconstruir porque ela não deixa traço: o que é evidente em um dado momento tem necessidade de ser dito ou escrito?" (JULIA, 2001, p. 15).

Para pesquisar os constituintes da disciplina História da Matemática, foram analisadas fontes documentais e orais, entre as quais citamos as Atas do Departamento de Matemática, a legislação oficial, planos de ensino e os depoimentos dos docentes que ministraram esta disciplina. O uso das fontes na construção do conhecimento histórico requer um rigor teórico e metodológico que propicie uma atmosfera de objetividade e cientificidade. Para isso, é necessário que tenhamos um olhar objetivo para os documentos: o essencial é enxergar que os documentos e os testemunhos "só falam quando sabemos interrogá-los...; toda investigação histórica supõe, desde seus primeiros passos, que a investigação já tenha uma direção" (LE GOFF, 1992, p. 27).

Adotou-se como procedimento, inicialmente, a análise de documentos, envolvendo a implantação da disciplina no currículo da licenciatura em Matemática e a condução dela observada nas Atas do Departamento, nas ementas; posteriormente, tomando como base os depoimentos orais dos docentes regentes bem como outros elementos constituintes (planos de ensino, trabalhos de alunos), realizou-se a crítica e a confrontação.

O exame das Atas do Departamento de Matemática da UFJF permitiu constatar que houve, até o momento, seis docentes regentes da disciplina História da Matemática. A análise documental aliada às entrevistas com os docentes regentes evidenciou três momentos distintos no ensino da disciplina História da Matemática que podem ser caracterizados da seguinte maneira: História da Matemática como disciplina para aprender Matemática, estudo da trajetória histórica da Matemática e a inclusão também de estudo sobre história da matemática escolar (FRAGOSO, 2011).

Observa-se que, nos períodos em que a disciplina História da Matemática foi tratada como conhecimento matemático, os docentes responsáveis eram matemáticos puros, enquanto nos períodos em que essa disciplina fora ministrada com um enfoque histórico, os docentes responsáveis pela disciplina são educadores matemáticos. Esse fator foi 
determinante na mudança de concepção da disciplina. O tratamento histórico da Matemática e, sobretudo, o estudo da história da matemática escolar tendem a contribuir de forma mais efetiva para a formação do futuro professor de Matemática por colocá-lo em contato com o objeto de sua futura atuação, o conhecimento matemático a ser ensinado.

No exame das Atas do Departamento de Matemática da UFJF, observa-se que, em 3 de outubro de 1980, foi discutida uma proposta de mudança curricular para o curso de licenciatura em Matemática. Entretanto, não há quaisquer detalhes sobre o porquê ou a natureza dessa mudança. Contudo, em depoimento, o professor Alberto Hassen Raad ${ }^{5}$, primeiro docente a ministrar História da Matemática na UFJF, afirma que ela foi inserida na licenciatura em 1981:

Em 1981, o curso de Matemática devia se adequar à nova licenciatura plena. Na ocasião, fui eleito coordenador do curso, [...]. Assim, o Departamento de Matemática me elegeu coordenador de curso de Matemática. Então coube a eu coordenar a nova reestruturação do curso de matemática, o que não fiz sozinho, fiz com os meus pares, mas, simplesmente, tem muito do meu modo de pensar, da minha maneira de ver o curso e, da filosofia que cada um tem. [...] Naquela ocasião, elaboramos uma nova licenciatura, onde foram introduzidas disciplinas novas, tais como: História da Matemática [...] (RAAD, 2010).

As atas do departamento registram que, em 18 de novembro de 1986, houve a indicação do Colegiado do Curso de Matemática (CCM) para que o professor Alberto fosse o regente da disciplina História da Matemática, no primeiro semestre de 1987. Assim, esse ano consagra-se como a primeira vez em que a disciplina História da Matemática foi oferecida aos estudantes do curso de licenciatura em Matemática, apesar de ter sido incorporada à grade curricular em 1981. Segundo o professor, a justificativa reside no fato de que, em função da nova proposta do curso implementado paulatinamente, essa disciplina foi ministrada pela primeira vez somente em 1987.

5 Docente da disciplina História da Matemática no período de 1987 a 1997. 
A Licenciatura (nova) foi introduzida progressivamente, período após período, a partir de 1984 e, desse modo, apenas a partir de 1987, a disciplina História da Matemática foi posta em carga, como última disciplina nova a ser introduzida no novo currículo (RAAD, 2010).

Nas atas do departamento não há vestígios da aceitação, empolgação ou rejeição com a inserção da História da Matemática no currículo. Entretanto, em conversa informal, o professor responsável pela defesa e inserção da disciplina no currículo do curso de Matemática deixou transparecer que alguns de seus colegas do Departamento de Matemática o designaram como responsável pela regência da disciplina porque ele a propôs.

O professor Alberto, em 1981, como coordenador do Curso de Matemática e docente do Departamento de Matemática, acreditava que o estudo da História da Matemática era importante para o estudante do curso de licenciatura em Matemática por enriquecer sua formação. Articulou e conseguiu então aprovar essa disciplina para compor o currículo do referido curso. Mestre em Matemática, ao ser indicado em 1987 para a regência da disciplina História da Matemática, nunca antes havendo lecionado essa disciplina, procurou então estabelecer contato com outros docentes com o intuito de verificar como outros colegas estavam trabalhando com a História.

Em 1987, participei de um Colóquio de História das Ciências promovido pelo Departamento de Filosofia da UNICAMP, que abordava René Descartes - o matemático e o filósofo. Na verdade, maior ênfase se deu aos aspectos filosóficos. O evento foi realizado numa estação de águas, Águas de Lindoia, para lá me dirigi com o propósito de encontrar-me com algum professor de História da Matemática, para ver como estavam desenvolvendo tal disciplina. Encontrei-me com o Prof. Irineu Bicudo, da UNESP de Rio Claro - SP, o Prof. Wanderley - IM-UFRJ (meu ex-professor) e mais dois ou três professores (Campinas, etc.). Percebi que estavam todos trabalhando de certo modo, da mesma forma, cobrindo os doze primeiros capítulos do Boyer, num curso de um período letivo (RAAD, 2010). 
É de se supor que assumir uma disciplina difícil de "disciplinarizar-se" (CHERVEL, 1990), como é a História da Matemática, pela própria natureza dos conhecimentos em jogo, deve ter causado insegurança e receio entre os professores do Departamento de Matemática. Como se disse, o próprio professor Alberto saiu em busca de referências para conduzir o curso. Adotou o modelo que lhe pareceu mais acertado para um curso de Matemática:

O curso de História da Matemática para mim é fundamentalmente um curso de Matemática. Esse é um ponto de vista que sempre defendi. Talvez um ponto de vista conservador para alguns, em que os aspectos epistemológicos e biográficos são preteridos em favor da abordagem matemática, fazendo um paralelo entre uma época, com roupagem nova, para mostrar a evolução das ideias, e bem como para apreciar as dificuldades hoje, de você raciocinar com uma abordagem retórica, não simbólica (RAAD, 2010).

Nessa proposta, os exercícios têm um papel fundamental e a História nada mais é que um pretexto para a resolução de problemas/ exercícios de Matemática, o que aproxima a História da Matemática das demais disciplinas do curso de Matemática. Em 1998, ocorreu a primeira renovação na regência da História da Matemática, assumindo o professor Amarildo Melchíades da Silva ${ }^{6}$, na época mestre em Educação Matemática. Envolvido também pelos preceitos contidos em sua pós-graduação, o professor redirecionou a disciplina dando-lhe uma abordagem epistemológica. A História deixou de ser mais uma disciplina para estudar Matemática e passou a tratar da história do conhecimento matemático, de como a Matemática foi historicamente construída.

Em termos curriculares, nessa regência e como coordenador do curso de Matemática, o professor Amarildo propôs uma extensão do plano de estudo, pois, anteriormente, o período histórico abrangia somente a História Antiga, sendo então ampliado até o século XIX.

${ }^{6}$ Doutor em Educação Matemática, foi regente da disciplina História da Matemática em 1998, 2005 a 2008. 
A única coisa que fiz durante a minha gestão como coordenador, foi ter ampliado o programa da disciplina, para chegar até o século XIX. Porque acreditava que ficar agarrado à antiguidade seria prejudicial ao aluno. Eu gostaria de pelo menos dar uma ideia ao aluno das transformações ou evolução da Matemática até o século XIX. Pelo menos o aluno teria uma panorâmica. Tive por base a minha experiência: quando eu fui fazer o mestrado, alguns dos meus colegas tinham essa visão panorâmica, eu tinha só a visão da antiguidade. Então, quando fiz esta sugestão de modificação, que foi aprovada pelo Colegiado do Curso de Matemática - CCM, eu objetivei que o aluno tivesse a visão global do século XIX, em termos de conhecimento matemático, para quando alguém o indagasse sobre este período, este aluno tivesse meios de tecer uma resposta de acordo com que havia estudado (DA SILVA, 2010).

No que tange à bibliografia, não houve modificação. Dessa forma, as obras traduzidas de Carl Benjamin Boyer e de Howard Eves eram e ainda são utilizadas quando se trata do ensino de História da Matemática. Entretanto, a forma com que tais textos foram adotados é o que determina o diferencial desses dois períodos. Isto é, no primeiro momento, esses textos foram usados para dar continuidade a um curso de Matemática. Num segundo, as leituras foram tratadas de forma epistemológica, nas palavras do professor. Ele procurava discutir com seus alunos o desenvolvimento histórico da Matemática, considerando os aspectos culturais, situando temporalmente os estudantes e assumindo uma postura crítica frente ao conteúdo apresentado no próprio livro.

Segundo o entendimento do professor Amarildo, há duas maneiras de efetuar a leitura da História da Matemática: uma leitura progressivista, que consiste em ler a história em busca de uma sucessão acontecimentos; e uma leitura epistemológica, que busca entender como as ideias matemáticas contidas em uma cultura estão organicamente articuladas e de que forma certas noções estão naturalmente excluídas dessa cultura:

Eu preferia o Boyer ao Eves. Porque, o Eves me causa um problema no prefácio, na introdução do livro, ele diz que um curso de História da Matemática é um curso de matemática. Puxa! Então, eu pensava, para 
que, então, ele utiliza a palavra história. Outro problema para mim é que o livro dele separa o conteúdo social/histórico da matemática. Assim, eu preferia o Boyer, porque ele é explicitamente progressivista. Então eu usava isso para ilustrar para os alunos, o entendimento de leitura epistemológica. Por exemplo, eu chegava para os meus alunos e falava: vocês concordam com que o Boyer menciona em relação aos egípcios, que eram fracos matematicamente? De início, os alunos aceitam, depois, indagam e dizem não! Neste momento, mostrava geograficamente, com a ajuda de um mapa, o Egito totalmente isolado e produzindo uma matemática, absurdamente, original. Isto fazia uma enorme diferença em termos de aprendizado. Este é um dos exemplos que ilustra como Boyer olha do presente para o passado e querendo colocar um crivo em cima das questões históricas antigas. Então, para mim, isso é um dos exemplos clássicos de uma leitura progressivista e não epistemológica. Assim, eu sempre ministrei o curso, a disciplina História da Matemática, tentando um enfoque epistemológico e quando eu chegava ao final do curso, meus alunos já tinham um senso crítico melhor (DA SILVA, 2010).

Com relação à avaliação, ocorreu a introdução de trabalho escrito, entregue ao fim do semestre, seguido de uma apresentação em forma de seminário, em substituição às provas tradicionais. No período anterior, as avaliações eram realizadas em forma de provas escritas e individuais, com a resolução e/ou a justificativa de problemas de Matemática. Provavelmente, essa escolha se baseava na concepção do professor Alberto, de que o curso de História da Matemática era um curso de Matemática. Quando a disciplina retornou para a responsabilidade de outros professores somente com formação em Matemática (mestres ou doutores), voltou a ser ministrada como um curso de Matemática, de forma tradicional, tanto em nível de ensino, quanto na forma de se realizar as avaliações.

A última transformação da disciplina ocorreu em 2009, quando assumiu a regência uma educadora matemática ${ }^{7}$ com atividade de pesquisa em história da educação matemática. Mantendo a abordagem histórica

\footnotetext{
7 Professora Dra. Maria Cristina Araújo de Oliveira integrante do Grupo de Pesquisa em História da Educação Matemática (GHEMAT).
} 
já praticada pelo professor Amarildo, a professora agregou elementos da história da educação matemática, particularmente leituras sobre o tema e a análise de livros didáticos de Matemática de diferentes momentos da história da educação matemática brasileira. Esse período marca a união do ensino de dois tipos de conteúdos: história do conhecimento matemático e história da matemática escolar.

A metodologia de ensino caracteriza-se pela discussão das leituras realizadas, apresentação de seminários e produção de um trabalho final. Tal transformação envolveu a consecução de uma nova ementa, a inserção de novas referências bibliográficas e novos instrumentos de avaliação: a produção de resenhas, a apresentação de seminários e a participação nas aulas.

O percurso delineado em alguma medida ratifica as considerações de Chervel (1990) quando relaciona a mudança do corpo docente com as transformações sofridas por uma disciplina no decorrer dos anos de sua existência curricular.

\section{Considerações finais}

O estudo histórico da trajetória da disciplina História da Matemática no curso de licenciatura em Matemática da UFJF revela três momentos de mudanças: inicialmente, ela é tratada como uma disciplina de Matemática; num segundo momento, há uma ruptura nessa abordagem e ela passa então a ser ministrada para se estudar historicamente a Matemática; o terceiro momento não caracteriza propriamente uma ruptura, mas, sim a inclusão de novos conteúdos, relativos à história da educação matemática, particularmente à história da matemática escolar.

Os esforços empreendidos pelo professor Alberto resultaram na introdução da disciplina História da Matemática no currículo do curso de licenciatura em Matemática da UFJF. Por mais de 10 anos, durante as regências do professor Alberto e de mais três professores, ela foi conduzida 
de acordo com a concepção de que um curso de História da Matemática é um curso de Matemática. Cabe salientar que todos esses docentes possuem formação exclusiva em Matemática.

Para além da proposição de Chervel (1990) de que a "taxa de renovação do corpo docente é um fator determinante” na transformação das disciplinas, o que se observa é a influência da formação dos professores responsáveis na abordagem realizada. Ao que tudo indica, a formação em Educação Matemática determinou a ruptura e a introdução de uma abordagem histórica para a disciplina História da Matemática. A formação e atuação em pesquisa dos docentes responsáveis pela disciplina exerceram uma influência determinante nos constituintes da disciplina: plano de ensino, bibliografia, metodologia, avaliação, entre outros.

De forma sintética, podem-se identificar duas tendências: História da Matemática como uma disciplina de Matemática ou como história do conhecimento matemático e/ou da educação matemática. Por si só, tais possibilidades já constituem indicativos da dificuldade de disciplinarização da História da Matemática. De outra parte, um dos elementos que contribuem na disciplinarização é o rol de conteúdos a serem ensinados. Se sobre eles houver consenso, há um núcleo comum que deve ser seguido. No caso da História da Matemática, em resoluções e decretos, não está incluído um conjunto de conteúdos a serem ensinados. Além disso, a análise das ementas e planos de ensino das universidades federais mineiras também não revelou consenso.

O modelo tradicional de formação do professor, conhecido como $3+1$, três anos de formação específica e um ano de formação pedagógica, embora muito criticado e tido como superado, ainda integra as práticas, mesmo com as novas diretrizes de formação. Tomando-se como referência a real dicotomia entre a formação específica e a formação pedagógica, a História da Matemática que versa sobre humanidades-história traz dificuldades aos matemáticos em tratá-la com um ensino diferente das disciplinas matemáticas. Isso não ocorre quando educadores matemáticos são responsáveis pela História da Matemática, provavelmente, pela natureza multidisciplinar requerida por sua formação. 
A disciplina História da Matemática, por ter um caráter que a difere das disciplinas de conteúdo matemático, bem como das disciplinas pedagógicas, tem um papel fundamental na formação dos futuros professores de Matemática. Tal disciplina ocupa, mesmo sem a estabilidade de outras disciplinas que compõem essa formação, um espaço consolidado no currículo do curso de licenciatura em Matemática de praticamente todas as instituições de ensino superior.

\section{Referências}

BRASIL. Ministério da Educação. Parecer CNE/CES 1.302/2001 de 6 de novembro de 2001. Diretrizes Curriculares Nacionais para os Cursos de Matemática, Bacharelado e Licenciatura. Brasília, DF, 6 nov. 2001. Disponível em: $\langle$ http://portal.mec.gov.br/sesu/arquivos/pdf/130201mat.pdf $\rangle$. Acesso em: 6 abr. 2010.

CHARTIER, R. La historia o la lectura del tiempo. Espanha: Editorial Gedisa, 2007.

CHERVEL, A. História das disciplinas escolares: reflexões sobre um campo de pesquisa. Teoria e Educação, Porto Alegre, n. 2, p. 177-229, 1990.

FRAGOSO, W. C. História da Matemática: uma disciplina do curso de Licenciatura em Matemática da Universidade Federal de Juiz de Fora. 2011. 210 f. Dissertação (Mestrado Profissional em Educação Matemática) - Instituto de Ciências Exatas, Universidade Federal de Juiz de Fora, Minas Gerais, 2011.

JULIA, D. A cultura escolar como objeto histórico. Revista Brasileira de História da Educação, Campinas, n. 1, p. 9-43, 2001.

LE GOFF, J. História e memória. Campinas: Ed. da Unicamp, 1992.

MIGUEL, A.; BRITO, A. de J. A história da matemática na formação do professor de matemática. Caderno CEDES, Campinas, v. 40, p. 47-61, 1996. 
RAAD, A. H. Entrevista concedida a Wagner da Cunha Fragoso, 11 mar. 2010, Juiz de Fora.

SILVA, A. M. da. Entrevista concedida a Wagner da Cunha Fragoso, 5 ago. 2010, Juiz de Fora.

SOUTO, R. M. A. História e Educação Matemática - História na formação do professor de matemática. In: ENCONTRO MINEIRO DE EDUCAÇÃO MATEMÁTICA “DESAFIOS ATUAIS DO PROFESSOR DE MATEMÁTICA”, ENCONTRO MINEIRO DE EDUCAÇÃO MATEMÁTICA 3., 2003, Belo Horizonte. Anais... Belo Horizonte: Sociedade Brasileira de Educação Matemática - Regional de Minas Gerais, 2003. CD-ROM.

Recebido: 17/05/2010

Received: 05/17/2010

Aprovado: 10/10/2010

Approved: 10/10/2010 